\title{
¿De país aislado a aliado preferido? Las relaciones entre Argentina y los Estados Unidos: 1976-1981 Wolf Grabendorff
}

Las relaciones argentinas con EE.UU. constituyen un caso clásico de relaciones asimétricas. Factores históricos, geopolíticos, económicos y estratégicos tanto como culturales han contribuido al hecho que, desde la Independencia a comienzos del siglo xix hasta hoy día, ningún país habrá tenido dificultades semejantes a los que tiene Argentina con su vecino distante. No obstante, en la historia argentina siempre hubo períodos de relaciones estrechas, hasta en parte cordiales, con EE.UU. Parece que ahora otra vez está comenzando tal período. Sin embargo, no cabe duda que, desde el punto de vista argentino, siempre se ha pagado un precio exorbitante por tales relaciones estrechas con EE. UU. Por eso es necesario analizar el porqué tanto de las fluctuaciones en las relaciones bilaterales como de su agrupación a partir de 1976.

\section{Garacteristicas de las relaciones}

Desde un punto de vista histórico, las relaciones entre Argentina y EE.UU. siempre han sido malas. La razón principal es que Argentina fue el único país latino que desde un principio, es decir, desde los comienzos del panamericanismo a fines del siglo pasado, no aceptaba la hegemonía implícita de EE.uU. en América Latina. Durante largo tiempo el concepto argentino era que EE.UU. dominara en América del Norte y Argentina en América del Sur. Hasta hoy en día Argentina sigue considerando a EE.uU. más como un rival que como un socio. Por ello, también el rol de Argentina en el sistema interamericano siempre ha sido el de retardar y de frenar, ya que Argentina a tiempo se había dado cuenta de que de este sistema no podría sacar grandes provechos. Así, no fue fortuito que Argentina fuera el último país miembro en ratificar tanto el Pacto de Río como la Carta de la OEA, con un retraso de varios años. Los argentinos, hasta mediados del siglo $\mathrm{xx}$, tenían entendido que su posición de "cabeza de puente europea" en América Latina les valdría de 
punto de partida más privilegiado en el sistema internacional que Io que hiciera la cooperación con América Latina, cuando no con América del Norte. Su posición frente a EE.UU. principalmente, aunque no exclusivamente, reside en este europeísmo, y tal presunción de sus recursos como del margen político nacional frente a la dependencia considerable del Imperio Británico cuenta entre las particularidades de la política exterior argentina.

Políticamente, los argentinos tomaron un mal camino cuando, durante la Segunda Guerra Mundial, no sólo le negaron confraternidad de armas a EE.Uv., sino que tan sólo después de la guerra, y de mala gana, se mostraron dispuestos a reconocer a EE.UU. como poder dominante del mundo occidental, y al mismo tiempo, siempre haciendo objeciones contra su hegemonía en América Latina. La integración cada vez mayor con Latinoamérica como respaldo contra EE.UU., cosa que se intentó sobre todo en la era peronista, fracasó por una variedad de razones. Hay que añadir que la inestabilidad interna de Argentina hizo más y más discutible su capacidad de aliado, cuando no de poder dominante en Latinoamérica. Al mismo tiempo, la introversión política típica del sistema político argentino después de la guerra no era muy adecuada para dar relieve a las relaciones con EE.uU., por lo menos desde la visión de Argentina. Las relaciones de Argentina con el poder preponderante de la región eran reactivas más que activas.

Económicamente, la cooperación no era de gran interés para ninguno de los socios desiguales. Para Argentina, EE.uv. representan la mayor competencia para sus propios productos en el mercado mundial -exceptuando el Canadá y Australia-. El volumen de comercio bilateral hasta ahora tampoco se ha desarrollado como para servir de firme pilar de las relaciones bilaterales (de las importaciones argentinas el $20 \%$ viene de EE.UJ., mientras que sólo un $10 \%$ de las exportaciones argentinas va allá). La transnacionalización, tan importante en América Latina en los años 60 y 70 , no afectó tanto a Argentina como a algunos otros estados, así que las inversiones estadounidenses hoy son de relativa poca importancia (2 mil millones de dólares comparado con un total de $5 \mathrm{mil} \mathrm{mi-}$ llones de inversiones extranjeras).

Tomando en cuenta las determinantes históricas tanto políticas como económicas, no se da gran margen para una cooperación bilateral estrecha o continua. Al contrario, es seguro que la existencia de algunos puntos sensibles, que en la historia de las relaciones habian vuelto a cobrar actualidad, ha contribuido a disminuir las pocas posibilidades de cooperación. 


\section{Intensidad de las relaciones}

La intensidad de las relaciones entre EE.UU. y Argentina fue excepcionalmente alta, tanto en sentido positivo como negativo, de 1976 a 1981. La razón principal es que la integración al sistema internacional no sólo de América Latina como región, sino sobre todo de los estados particulares más importantes, puso a EE.UU. en la necesidad de reevaluar, y respectivamente, asegurar su influencia en ciertos países y regiones. Después del golpe de 1976 sin duda hubo oportunidad de una orientación manifiestamente pro EE.UU. en las relaciones exteriores argentinas. Durante este período también el interés de EE.UU. en Argentina aumentó considerablemente debido a la creciente independencia de la política brasileña en América Latina. La política de Martínez de Hoz se percibió como garante de los intereses económicos de EE.UU. y el Gobierno militar como factor estabilizador después del desorden interno y los conflictos rayando en guerra civil de los años precedentes.

Pero, la estructura de las relaciones bilaterales fue cambiada rápidamente por la elección de Carter como Presidente y por su política orientada de acuerdo con los derechos humanos. Argentina se convirtió en "caso de prueba" para la realización de la nueva política exterior, y el poder dominante del Occidente empezó a denegar sistemáticamente la legalidad de la Junta Militar argentina. Tomando en cuenta la dependencia, de todos los regímenes ilegales latinos y sobre todo los militares, de la legitimación por el extranjero, este cambio de política constituía un punto muy crítico en la historia de las relaciones bilaterales. Las disensiones con EE.UU. produjeron un efecto de "bumerang", por decirlo así, transformándose en el aglutinante más fuerte para las elites de la política argentina. Especialmente en los añós 1977 y 1978 fue posible, por una estratagema ingeniosa, interpretar toda crítica de la política de derechos humanos, o, mejor dicho, de la ausencia de tal política, como crítica de la nación, activando así un mecanismo de defensa nacionalista contra el intervencionismo de EE.UU.

Es interesante que todas las disonancias entre la Administración de Carter y la Junta Militar se caracterizan por su referencia a cuestiones de soberanía y prestigio, y no, como vale para el Gobierno de Reagan, a cuestiones militares, estratégicas, geopolíticas, o sea, económicas y de desarrollo. En la discusión de los derechos humanos, de la transferencia de armas, de la posibilidad de un camino propio en la política nuclear, y del boicot de trigo de 1980, se trataba cada vez el tema de hasta qué punto EE.uv. lograrían imponer ciertas condiciones y normas de conducta en Argentina. Incluso en dos conflictos regionales que resultaron en disonancia con EE.UU., a saber el conflicto con Chile sobre el Canal Beagle y el de la participación argentina en el golpe boliviano, la cuestión de la soberanía 
argentina, es decir, de su libertad de acción en las relaciones exteriores, fue el asunto esencial de las disonancias.

Con referencia al punto central, que es la posición de la Junta Militar frente a los derechos humanos, las élites de la política argentina y sobre todo los militares, se sintieron ofendidos, en particular por la manera en que EE.uU. utilizaba la política de derechos humanos como instrumento en otros ámbitos. Para inducir a Argen. tina a adoptar una actitud más moderada para con la oposición interna, EE.UU. no solamente redujo la ayuda militar (que los argentinos, por consiguiente, rechazaron en su totalidad en 1977), sino que también logró una suspensión de créditos en las votaciones de bancos internacionales como el BID y el Banco Mundial. Además, las declaraciones públicas a menudo se hacian de manera muy brus$\mathrm{ca}$, y finalmente hubo bastante presión diplomática (aunque todas las gestiones quedaron sin resultado, como en el caso de $\mathrm{la}$ de $\mathrm{Pa}$ tricia Derian por los derechos humanos en 1977, de Gyrus Vance por la política nuclear en 1977, y de Andrew Goodpastor por el boicot de trigo en 1980).

Como Sudáfrica y también, en algunos casos, Israel, Argentina entre 1977 y 1980 consiguió eludir toda presión de parte de EE. UU. adoptando una especie de mentalidad de asedio. Esto contribuyó mucho a la consolidación de los militares y a partir de 1978 se vio un reblandecimiento de la actitud estadounidense, por lo menos en el campo económico.

La elección de Reagan en EE.UU. puso fin al período duro para los militares argentinos. La denegación de legalidad de los años 1977 a 1980 se cambió en manifiesta. Otra vez Argentina fue declarada caso de prueba para E..uu., esta vez en cuanto se trataba de anular una política de derechos humanos equivocada en la opinión de la nueva Administración, y de considerar otros determinantes de las relaciones bilaterales. Entre éstos cuentan sobre todo la actitud anticomunista, la situación geopolítica y la disposición argentina a dar un apoyo bastante amplio a EE.UU. en cuestiones globales, a diferencia de muchos otros países latinoamericanos. El motivo decisivo de tal "galanteo" de Argentina no sólo era un cambio repentino de la percepción estadounidense, sino también las consecuencias estratégicas de la cooperación intensificada entre Argentina y la Unión Soviética en los años 70. Naturalmente, esta cooperación de ningún modo se fundaba en intereses ideológicos comunes, sino exclusivamente en la necesidad de buscar un mercado a la larga seguro para los productos primarios argentinos. El boicot de trigo de EE.UU. produjo una excelente oportunidad para establecer una cooperación más estrecha entre Argentina y la Unión Soviética. De acuerdo con la estrategia de EE.Uu., que intentaba dejar la influencia soviética en la posible fuera del hemisferio occidental, en- 
tonces se hizo necesario "galantear" a Argentina para imposibilitar cualquier expansión soviética, incluso a largo plazo.

Otro motivo igualmente pertinente a la política exterior fue la diferenciación hecha por EE.UU. entre regímenes autoritarios y totalitarios (Kirkpatrick). Tenía por objeto demostrar que regímenes autoritarios como el argentino eran capaces de transformarse en gobiernos democráticos y pluralistas, y que por eso no había que confundirlos políticamente con los regímenes totalitarios (por los que exclusivamente se entienden regímenes comunistas).

La intensidad de las relaciones Argentina-Ez.uv. bajo el Gobierno de Reagan se caracteriza por una variedad de acciones, a saber por la invitación de Viola a Washington ya antes de su asunción del mando, acción diplomática muy desacostumbrada entre EE.UU. y estados latinos, por la moción propuesta de "re-normalizar" la transferencia de armas -considerablemente reducida por el Congreso en la era Carter en vista de las violaciones de derechos humanos-y, finalmente, por una orden del Presidente de cambiar de política en el voto de créditos argentinos con los bancos internacionales, es decir, cesar de aplicar las normas de derechos humanos.

La agenda de diálogos y problemas ha cambiado fundamentalmente en comparación con los años pasados. La defensa del Atlántico Sur sin duda ocupa el primer lugar. La proposición de formar un Comando del Atlántico Sur, ya hecha por el Presidente Ford en 1975, ha ganado en actualidad, sobre todo con referencia al desarrollo de la situación en Namibia y la posible inestabilidad de Sudáfrica. Para el Gobierno de Reagan, con su fijación en sus intereses militares a nivel global, la discusión sobre la formación de un pacto del Atlántico Sur (OTAS), que está al fondo de todo esto, llegó a ser un asunto decisivo de la cooperación con Argentina. En segundo lugar, Argentina se cuenta entre los pocos países latinoamericanos dispuestos a despachar tropas tanto a El Salvador -donde ya hay asesores argentinos para la lucha antiguerrilia- como al Sinaí, si EE. vU. lo deseara dentro de un acuerdo multilateral. Aparte de tales cuestiones militares, la posición económica argentina tiene un papel cada vez más importante. Como EE.UU., opinan que el hemisferio occidental a mediano plazo tendrá que llegar a la autarquía, sobre todo en cuanto a energía y materias primas, las reservas de petróleo argentinas tanto en la base continental como en Patagonia han ganado en importancia. Se ve claramente que Argentina, potencial país exportador de petróleo, está sujeto al mismo mecanismo que hizo ganar a México y Venezuela, países exportadores de petróleo, en influencia a costa del Brasil, país importador de petróleo. El poder mercantil en alimentos que Argentina podría ejercer en el futuro junto al Ganadá y EE.UU, constituye un factor adi- 
cional en las deliberaciones de EE.UU., que ve en Argentina un pilar esencial de una estrategia global a largo plazo.

Con respecto a la política interior; Argentina es considerada como un país que ya terminó sus luchas internas y, por eso, como factor estabilizador es muy apreciado frente a otros estados que no se estiman estables a largo plazo, ni mucho menos.

Esta reevaluación de la posición estratégica, económica y global argentina constituye, en opinión de las elites de la política del país, un enorme respaldo para sus intenciones en la política interior y exterior. Además, es considerada como afirmación de que "los verdaderos amigos en Washington" reconocen el valor de la posición argentina, y que, por lo tanto, la disensión con el Gobierno Carter entre 1977 y 1980 "valió Ia pena".

\section{El provecho de las relaciones}

Tanto como el Brasil, Argentina es una nación con un sentido patriótico extremo. La decadencia causada por la crisis económica y la inestabilidad política a través de varias generaciones, por decirlo así, traumatizó las elites de la política del país. La posibilidad de programar un ascenso, debido al cambio del punto de partida en las relaciones bilaterales y globales, crea oportunidades jamás sospechadas para los jefes políticos, oportunidades tal vez realizables incluso en la política interior. Sobre todo bajo el aspecto de la política exterior los intereses comunes con los EE.UU. de Reágan son de verdad considerables. En ambas Administraciones, la visión geopolítica predomina y los conceptos de amenaza se parecen mucho. En 1981 las relaciones bilaterales entraron en una etapa donde los gobiernos se creen mutuamente aprovechables tanto en la política exterior como, en el caso de Argentina, en la anterior. Ambas partes opinan poder sacar provecho de la posición del otro dentro de una estrecha cooperación.

Evidentemente, este provecho es sobre todo coyuntural, pues en la mayoría de los casos cuando hubo disensiones en los íltimos años, fue EE.UU, y no Argentina el que tuvo que transigir, aparentemente por causa del cambio de Gobierno o de las percepciones. Esto vale para la realización de derechos humanos, el boicot del trigo y también los problemas nucleares, puesto que EE.Uv. hoy ya no está insistiendo en la adhesión de Argentina al Acuerdo de Tlatelolco.

Por el lado estructural, sin embargo, el provecho no se ve tan manifiesto desde el punto de vista argentino. Es extremadamente improbable que la esperanza de volver a la estabilidad y la prosperidad de los años dichosos, fundadas en la asociación al Imperio Británico, sea satisfecha por un reestablecimiento de la Pax Americana en el balance político global actual. También es dudoso si 
los provechos de la disposición argentina a cooperar con los objetivos globales de EE.UU. resultarán realizables al interior. Además, a mediano plazo hay que contar con nuevos roces con Brasil, mientras que los dos desde 1979 parecían haber vencido su clásico antagonismo. Entre los estados latinoamericanos, hay una tendencia más fuerte a una integración independiente al sistema internacional que a lograr una posición internacional fortificada con el apoyo de EE. UU.

Los provechos de las relaciones con EE. UU. para la política interior argentina se pueden resumir en que el rechazo de la intervención de Carter sirvió de factor esencial para la unión de las diferentes facciones militares, y además favoreció en gran medida el nacionalismo del país. El apoyo de Reagan es otro factor de estabilización, aunque se manifiesta de otra manera, a saber, en el campo económico, y más todavía en el militar. En cuanto a la política exterior, el camino está allanado hacia un margen de acción más amplio. Especialmente frente al mundo occidental, el aislamiento de los años 1977 a 1980 ha sido roto en gran parte. Por otro lado, Argentina tiene que contar con efectos no sólo en sus relaciones con Cuba y Brasil, sino también con el Movimiento de los No-Alineados, del que sigue siendo miembro. También se puede ver un provecho político en la posición fortificada frente al Brasil y a la Comunidad Europea, por la que Argentina se ha visto muy desilusionada en los últimos años. En Chile, país que Reagan sigue ignorando, su influencia es evidente en el asunto del Canal Beagle, y es seguro que en Argentina hay esperanzas de transformarse en un poder preponderante en la zona atlántica sur, si Argentina estuviera dispuesta -otra vez al contrario del Brasil- a formar una alianza con EE.UU. y Sudáfrica.

Argentina es el único de los grandes estados latinoamericanos -con referencia a su importancia internacional- (Brasil, México, Venezuela, Cuba), que todavía no ha encontrado un puesto fijo en el sistema internacional. Mas, Argentina corre el peligro de tomar una decisión errónea, estableciendo hechos históricos, como lo hizo con la Asociación al Imperio Británico, existente todavía cuando la posición del Imperio en el sistema internacional ya había cambiado tanto que Argentina no podía sacar mucho provecho de ella. Algunas veces, la política exterior argentina ha sido determinada por el deseo de salir del aislamiento. Una decisión en favor de un rol de instrumento de EE. Uu., tal como el de Israel en el Próximo Oriente o el de Sudáfrica en Africa podría ser un error igualmente grave, tomando en cuenta la situación global. 
Argentina siempre ha sido un país sumamente dependiente - pero en forma de "dependencia consentida" (Félix Peña) - y la nostalgia de muchos argentinos parece estar buscando otra vez una dependencia tan favorable. Si a tal dependencia se unen prestigio y prospericlad económica, la decisión no será difícil para los líderes de la política exterior. $Y$ es exactamente la alianza política con EE. UU. bajo Reagan que parece prometer tal posición. Es verdad que la afinidad estructural al Tercer Mundo, la avanzada integración regional en Latinoamérica $y^{\prime}$ las relaciones culturales con Europa Occidental tanto como las experiencias históricas no concuerdan con tal decisión. Pero muchos argentinos ven esta oportunidad como la salida de medio siglo de crisis. 